Special issue of the International Conference on Computational and Experimental Science and Engineering (ICCESEN 2014)

\title{
Magnetic Properties and Resistivity Measurement of Nanocrystalline $\mathrm{Cu}_{70} \mathrm{Fe}_{18} \mathrm{Co}_{12}$ Alloys
}

\author{
W. LASLOUnI ${ }^{a, b, *}$, Z. HAMlati ${ }^{a, b}$ AND M. AzZAZ ${ }^{b}$ \\ ${ }^{a}$ Département de Physique, Faculté des Sciences, Université de Blida, Algeria \\ ${ }^{b}$ Laboratoire de Science et Génie des Matériaux, U.S.T.H.B, Alger, Algeria
}

\begin{abstract}
The mechanical alloying process has been used to prepare nanocrystalline $\mathrm{Cu}_{70} \mathrm{Fe}_{18} \mathrm{Co}_{12}$ alloy from elemental $\mathrm{Cu}, \mathrm{Fe}$ and $\mathrm{Co}$ powders in a planetary ball mill under argon atmosphere. The interdiffusion of $\mathrm{Cu}, \mathrm{Fe}$ and $\mathrm{Co}$ leads to a heterogeneous solid solution with $\mathrm{Cu}-\mathrm{Fe}-\mathrm{Co}$ rich environments after $12 \mathrm{~h}$ of milling. The end product is a mixture of a highly disordered structure, fcc- $\mathrm{Cu}(\mathrm{Fe}-\mathrm{Co})$, phase having different microstructural and structural parameters. For all the elaborate series, the evolution of coercive field and the remanence according to the time of milling is analyzed. The coercivity, $H_{c}$, decreases rapidly up to $8 \mathrm{~h}$ of milling to about $0.3 \mathrm{~A} / \mathrm{m}$ and then the coercivity, increases to a maximum at $54 \mathrm{~h}$. The influence of the time of milling at the resistivity of these alloys is shown.
\end{abstract}

DOI: 10.12693/APhysPolA.128.B-190

PACS: 81.07.-b, 81.20.-n, 81.20.Ev, 81.07.Wx

\section{Introduction}

Nanostructured materials continue to receive a great importance in different fields of material engineering because of their outstanding physical, mechanical, magnetic and chemical properties which are different from those of the coarse-grained counterparts [1-3]. Significant progress has been made in developing several processing techniques to prepare nanostructured materials. Among these techniques, mechanical alloying (MA) is a solid state synthesis method to prepare nanocrystalline alloy/compound powders by milling the elemental powders in an appropriate ball mill. Extreme local pressures and temperatures, engendered for a small milling time during repeated ball-powder-ball collisions, lead to the powdered materials transfer by diffusion and eventually, to the formation of new phases which cannot be obtained by other techniques of preparation [4-6].

In this study, the chosen composition is $\mathrm{Cu}_{70} \mathrm{Fe}_{18} \mathrm{Co}_{12}$, which is quite different from all previous alloys in this system. Detailed electron microscopy observation and X-ray energy dispersive analysis (EDX) have been performed on this material; followed by magnetic and resistivity measurements.

\section{Experimental procedure}

The $\mathrm{Cu}_{70} \mathrm{Fe}_{18} \mathrm{Cu}_{12}$ alloy was prepared by $\mathrm{MA}$ from $\mathrm{Cu}$, $\mathrm{Fe}$ and Co elemental powders. A mixture of appropriate amounts of $\mathrm{Cu}, \mathrm{Fe}$ and $\mathrm{Co}$ powders was mechanically alloyed, using a RETSCH PM400 model with stainless balls, under an Ar atmosphere, with the balls to powder weight ratio of 20:1. Mechanical alloying was performed for several processing times: $4,8,12,24,36$ and $54 \mathrm{~h}$, respectively. The particle size, morphology and chemical

*corresponding author; e-mail: laslouni-warda@yahoo.fr composition of the $\mathrm{Cu}-\mathrm{Fe}-\mathrm{Co}$ powder have been studied after every milling cycle on a JEOL 6360 microscope equipped with EDX analyzer. The magnetic measurement of the samples were performed at low frequency (at room temperature) in a variable field created by two coils vacuum, the sample is placed at the center of two coils connected to a magnetic induction meter (tesla meter). This arrangement allows us to trace the hysteresis loops. The variation of the resistivity was measured by the four-point method.

\section{Results and discussion}

\subsection{Electron microscopy and analysis}

The powder obtained after $12 \mathrm{~h}$ of milling shows a bright aspect and large distribution. Observation under scanning electron microscopy (SEM) showed that the most of the particles have a size ranging from $15 \mu \mathrm{m}$ to $0.5 \mathrm{~mm}$, in the case of $\mathrm{Co}-\mathrm{Fe}-\mathrm{Co}$ which was milled for different times: 12,24 , and $54 \mathrm{~h}$. There was observed the presence of aggregates having an important size and flattened shape (Fig. 1c). The same order sizes are observed in the literature by Lardé [7] and Galdeano [8].

The results of X-ray mapping of the powder milled $12 \mathrm{~h}$ show a homogeneous distribution of the pure elements (copper, iron and cobalt) in the particles. On the base of these results we can say that beyond $12 \mathrm{~h}$ of milling, the powders became homogeneous to scale the $\mu \mathrm{m}$ (Fig. 2).

\subsection{Magnetic measurement}

The variation of coercivity $\left(H_{c}\right)$ with milling time is shown in Fig. 3a.

In this alloy, we observed the coercivity decreases in the early hours of milling, the minimum value of $H_{c}$ is about $0.3 \mathrm{~A} / \mathrm{m}$. This reduction coincides with the diffusion of cobalt into the copper. Beyond $8 \mathrm{~h}$ of milling, the coercivity increases to a maximum at $54 \mathrm{~h}$. The increase of $H_{c}$ can be explained by the presence of stresses introduced during prolonged milling. 

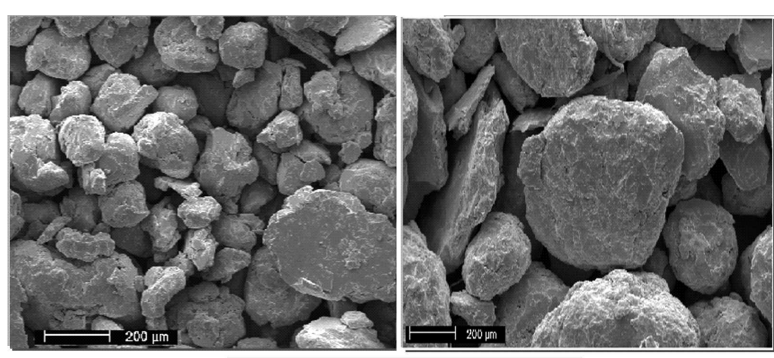

(a)

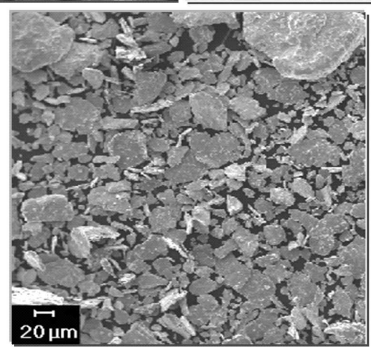

Fig. 1. Powder morphology and particle size of alloy $\mathrm{Cu}_{70} \mathrm{Fe}_{18} \mathrm{Co}_{12}$ : (a) $12 \mathrm{~h}$, (b) $24 \mathrm{~h}$ and (c) $54 \mathrm{~h}$.

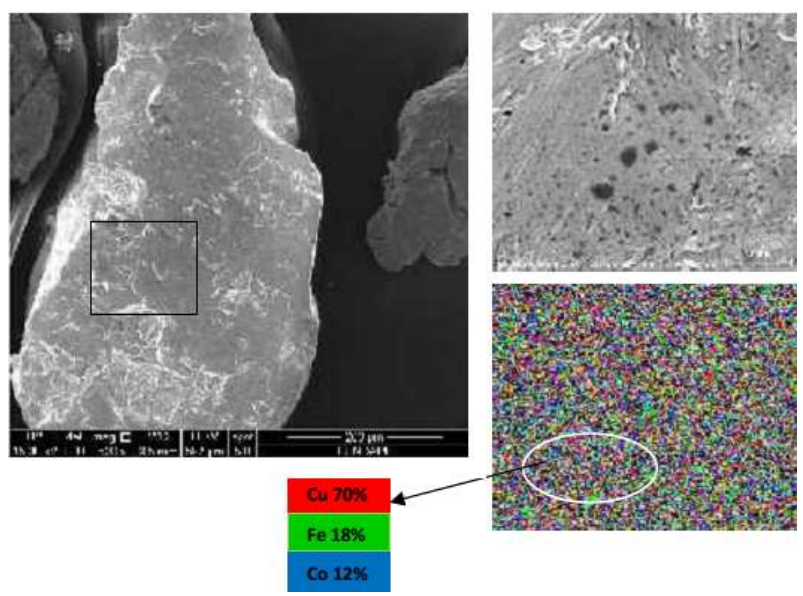

Fig. 2. Mapping a particle $\mathrm{Cu}_{70} \mathrm{Fe}_{18} \mathrm{Co}_{12}$ of milling. Elements map represent: in red the distribution of iron, in blue the distribution of cobalt and in green the distribution of copper.

The curve of the remanence is shown in Fig. 3b. The remanence $M_{r}$ decreases rapidly up to $8 \mathrm{~h}$ of milling then increases to $1.6 \mathrm{~T}$ after $48 \mathrm{~h}$. The small values of $M_{r}$ may be attributed to by the small magnetic particles which are typically single domains, or else by the introduction of constraints in the alloy.

\subsection{Resistivity measurement}

The variation of resistivity and the grain size are shown in Fig. 4. The high energy milling leads to the dispersion of magnetic elements (iron and cobalt) in the nonmagnetic matrix (copper) and this slows the movement of the current. The refinements of the crystallites size induced an increase in the number of grain boundaries. We have observed a slight decrease in resistivity between

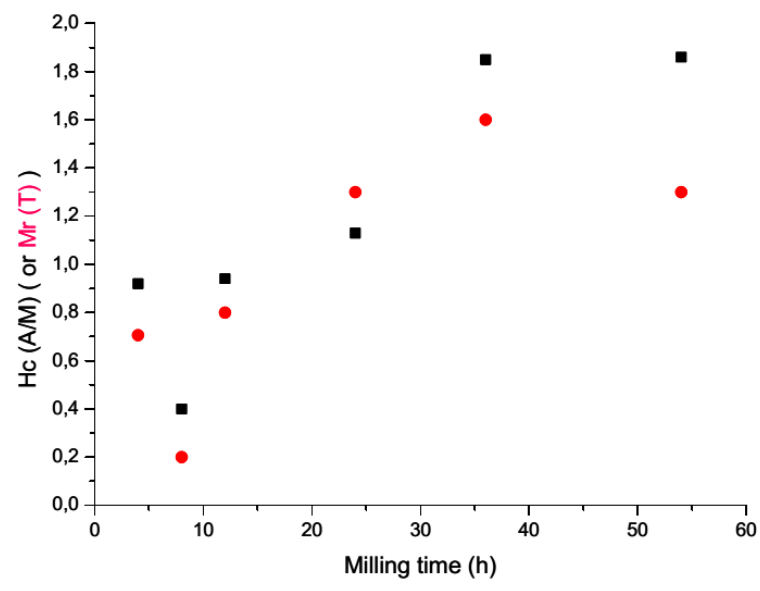

Fig. 3. Variation of: coercivity (squares) and remanence (circles) as a function of milling time.

8-12 h of milling which can be linked to the morphology of the powders.

Observations SEM made on these samples show the presence of large agglomerates, whereby the current flow is promoted in the continuous medium and uniform.

A slight increase in the value of resistivity is observed compared to the stored values in the binary alloys $\left(\mathrm{Cu}^{-}\right.$ $\mathrm{Co}, \mathrm{Cu}-\mathrm{Fe}$ ). Adding together the two transition elements (iron and cobalt) in the copper matrix by mechanosynthesis raised somewhat the values of the resistivity of the mixture.

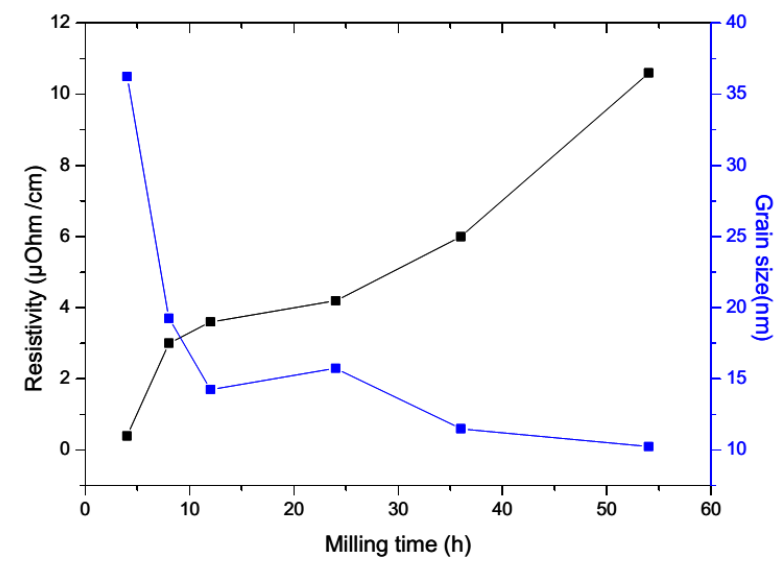

Fig. 4. Crystallite size and resistivity evolution as a function of milling time for $\mathrm{Cu}_{70} \mathrm{Fe}_{18} \mathrm{Co}_{12}$.

\section{Conclusion}

Analysis of the samples shows that they are homogeneous on the micron scale after a few hours of milling. SEM reveals the morphological evolution of the powder milled and the importance of the milling conditions to the evolution of the grain size. The study of magnetic properties shows that there are magnetic interactions between magnetic precipitates. These interactions seem to lead 
to the formation of regions magnetically coherent multi precipitates mutually coupled within each region, causing reorientation of the magnetic moments of ferromagnetic behavior. The results obtained show that the alloys consist of a granular mixture of hard magnetic phase (cobalt) and soft (iron) show a soft ferromagnetic behavior. The study of the electrical behavior reveals the increased electric resistivity as the milling time increases.

\section{References}

[1] C.C. Koch, Nanostruct. Mater. 9, 13 (1997).

[2] C. Suryanarayana, Prog. Mater. Sci. 46, 1 (2001).
[3] D.L. Zhang, Prog. Mater. Sci. 49, 537 (2004).

[4] S. Alleg, M. Ibrir, N.E. Fenineche, S. Azzaza, R. Bensalem, J.J. Suñol, J. Alloys Comp. 494, 109 (2010).

[5] M.S. El-Eskandarany, Mechanical Alloying for Fabrication of Advanced Engineering Materials, Noyes Publication, New York 2001.

[6] W. Tebib, S. Alleg, J.M. Greneche, Int. J. Nanoparticl. 3, 237 (2010).

[7] R. Lardé, Ph.D. Thesis, Université de Rouen, 2004.

[8] S. Galdeano, Ph.D. Thesis, Université Paris 7, 2001. 